\title{
Relações entre ginástica e saúde no Rio de Janeiro do século XIX: reflexões a partir do caso do Colégio Abílio, 1872-1888
}

\section{The relationship between} physical education and health in Rio de Janeiro in the nineteenth century: reflections based on the case of Colégio Abílio, 1872-1888

Victor Andrade de Melo

Professor, Programa de Pós-graduação em História Comparada/ Instituto de História/Universidade Federal do Rio de Janeiro (UFRJ); coordenador, Sport: Laboratório de História do Esporte e do Lazer. Largo de São Francisco, 1, sala 311

20051-070 - Rio de Janeiro - RJ - Brasil

victor.a.melo@uol.com.br

\section{Fabio de Faria Peres}

Pós-doutorando, Programa de Pós-graduação em Estudos do Lazer/ Universidade Federal de Minas Gerais; pesquisador, Sport: Laboratório de História do Esporte e do Lazer (UFRJ).

Largo de São Francisco, 1, sala 311

20051-070 - Rio de Janeiro - RJ - Brasil

peres@ensp.fiocruz.br

Recebido para publicação em setembro de 2014.

Aprovado para publicação em dezembro de 2014.

http://dx.doi.org/10.1590/S0104-59702016005000020
MELO, Victor Andrade de; PERES, Fabio de Faria. Relações entre ginástica e saúde no Rio de Janeiro do século XIX: reflexões a partir do caso do Colégio Abílio, 1872-1888. História, Ciências, Saúde - Manguinhos, Rio de Janeiro, v.23, n.4, out.-dez. 2016, p.1133-1151.

\section{Resumo}

$\mathrm{O}$ artigo discute as relações entre ginástica e saúde no Rio de Janeiro do século XIX a partir do caso de uma das mais prestigiosas escolas do período: o Colégio Abílio. Mais do que descortinar os discursos que cercavam o oferecimento da prática na instituição, busca-se compreender seus diferentes arranjos no cotidiano escolar. Foram utilizadas duas fontes de natureza diferenciada: periódicos publicados na cidade e o romance $O$ Ateneu, de Raul Pompéia. Conclui-se que o desafio que se apresenta para melhor entender a presença social da ginástica é captar a multiplicidade de apreensões que a cercavam no período em tela.

Palavras-chave: ginástica; saúde; educação física; história do esporte; Colégio Abílio.

\section{Abstract}

This article discusses the relationship between physical education and health in Rio de Janeiro in the nineteenth century, drawing on the case of one of the most prestigious schools at the time, Colégio Abilio. Rather than merely revealing the discourses that surrounded the provision of physical education at the school, we seek to comprehend the different ways in which it was incorporated into its educational routine. Two sources of different kinds were used: newspapers published in the city and the novel O Ateneu, by Raul Pompéia. We conclude that the challenge in understanding the social presence of physical education in the period in question is how to pick up the multiple apprehensions that surrounded it.

Keywords: physical education; health; gym; history of sport; Colégio Abílio. 
A presença da ginástica no cotidiano do Rio de Janeiro do século XIX é um tema ainda não suficientemente explorado. De toda forma, há indícios de que a prática teve algum grau de importância na capital (Peres, Melo, 2014a), mais comumente relacionada a preocupações e iniciativas ligadas à saúde e à educação (Gondra, 2004; Peres, Melo, 2014b). ${ }^{1}$

No Brasil, desde a década de 1830, a ginástica foi objeto de reflexão de médicos, tratada nas instituições a que estavam vinculados. O tema, por exemplo, foi abordado nos periódicos da antiga Sociedade de Medicina do Rio de Janeiro, depois convertida em Academia Imperial de Medicina, ${ }^{2}$ bem como em veículos de difusão como o Diário de Saúde (1835-1836), o Arquivo Médico Brasileiro (1844-1848) e o Anuário Médico Brasileiro (1886-1897).

Não se deve, contudo, crer que o estabelecimento da relação entre ginástica e saúde se deu de forma automática: tratou-se de uma construção gradual e nem sempre harmônica. No decorrer do século XIX, um saber sobre a prática foi sendo paulatina e simultaneamente incorporado e difundido por atores e instituições a que se atribuía o domínio do conhecimento médico. Delineava-se uma "ginástica médica", um olhar específico sobre a modalidade que existia em diferentes espaços sociais (Peres, Melo, 2014a).

Logo a ginástica passou a ser citada como parte da terapêutica em estudos sobre o tratamento de moléstias de diferentes naturezas, tais como enxaqueca, anemia, tísica, paralisia, alienação mental, doenças do coração, entre outras. ${ }^{3}$ Mais ainda, compreendida na interseção entre saúde privada e saúde pública, a prática foi concebida como importante ferramenta para o desenvolvimento físico, moral e intelectual das crianças e da "mocidade" (Peres, Melo, 2014a).

Não por acaso, diversos investigadores já assinalaram como a relação entre práticas corporais, higiene e saúde estruturou projetos para a educação nacional (Gondra, 2004; Cunha Júnior, 2008; Peres, Melo, 2014b). Um entre tantos exemplos dessa perspectiva pode ser identificada no artigo "Utilidade e necessidade da ginástica", do facultativo Emilio Joaquim da Silva Maia, publicado na Revista Médica Fluminense em julho de 1840. Membro da Academia Imperial de Medicina, da Academia Filosófica e do Instituto Histórico e Geográfico Brasileiro, ele defendeu que a modalidade, a seu ver uma parte da medicina, deveria ser adotada de forma generalizada nas escolas brasileiras, especialmente no Colégio Pedro II.

O tema foi mesmo tratado em algumas sessões da Academia Imperial de Medicina. Entre outros, pronunciaram-se sobre o assunto Francisco Paula Candido, Augusto Renato Cuissart, Francisco Júlio Xavier e Joaquim Vicente Torres Homem. Os posicionamentos demonstram que havia divergências, girando as discussões em torno do modelo mais adequado de exercícios e da possível contribuição da ginástica para o combate das moléstias que assolavam a Corte. De toda forma, houve dois pontos consensuais: a necessidade de introduzir a prática nas escolas, bem como de produzir conhecimentos que fossem adequados à realidade brasileira, não somente reproduzindo compreensões estrangeiras.

Vale destacar que o processo de consolidação da autoridade médica sobre a ginástica coincide com uma maior proximidade dos facultativos com o Estado, que recorria cada vez mais a eles a fim de se posicionar em relação a diversas de suas iniciativas. Indícios dessa maior interlocução com a estrutura administrativa imperial podem ser vistos nos relatórios anuais do Ministério dos Negócios do Império (1831-1889). 
Diversos documentos da Inspetoria Geral de Instrução Primária e Secundária aventaram as relações entre a prática e a saúde no cenário escolar. Muitos cargos da estrutura governamental, inclusive, foram ocupados por esculápios que a concebiam como uma estratégia pedagógica indispensável. Esse foi o caso do doutor Abílio Cesar Borges, que integrou o Conselho de Instrução Pública da Corte entre 1871 e 1877.

Do mesmo modo, em diversas ocasiões a ginástica foi abordada nos relatórios da Junta Central de Saúde Pública, órgão normalmente dirigido por médicos. Era destacada a necessidade de considerar com mais seriedade o tema, em particular sua introdução nas escolas, tendo em conta que seria uma estratégia para melhorar as condições de saúde da Corte. De fato, ao defenderem a importância da prática, mesmo com imprecisões, os facultativos também sugeriam a adoção de alguns princípios para seu ensino.

Assim sendo, a relação da ginástica com as preocupações e noções de saúde, intermediada pelas iniciativas médicas, é sem dúvida uma dimensão relevante a ser considerada na investigação do objeto. Deve-se destacar que, nesse cenário, não apenas a escola foi representada como um dos domínios do saber médico, como a "própria invenção da educação escolar no Brasil" seria caudatária de uma "matriz médica" (Gondra, 2004, p.83).

A ginástica, em particular, mesmo "antes de chegar ao Brasil", se inscreveria no conjunto de "prescrições higiênicas voltadas para a 'educação do corpo", possuindo como "objetivo primeiro preservar forças físicas e psíquicas, o vigor do corpo e, sobretudo, prevenir os grandes e pequenos males" (Soares, 2009, p.134; destaques no original).

Logo, não seria por acaso que o espraiamento da prática no Novo Mundo carregasse sentidos da sua gênese, uma "herança" do Velho Continente. Como sugere Soares (2009), fazendo referência ao clássico Le souci du corps: histoire de l'hygiène en éducation physique, de André Rauch (1983, p.134; destaques no original):

A 'velha ginástica', que no início do século XIX adquire um status oficial no Velho Continente e acompanha seus imigrantes que chegam ao Novo Mundo, é, portanto, uma prática corporal que encarna posturas normativas inspiradas na geometrização de gestos, em suas inúmeras combinações, e, ainda no registro das forças e seu desenvolvimento, nas justificações fisiológicas que permitem uma análise mais acurada acerca das funções orgânicas; enfim, tudo o que concerne às mais vastas ambições acerca da 'saúde'.

Assim, a história da prática corporal - a partir de continuum entre o lado de cá e o lado de lá do Atlântico - iria ao encontro de uma racionalização do uso do corpo, sustentada pelos emergentes saberes médicos e pelas novas tecnologias; processo próximo ao identificado por Vigarello (2003a, 2003b, 2004, 2009) na França do século XIX, no qual, segundo o autor, se estabeleceria uma "ruptura" e uma "renovação" da visão acerca dos exercícios físicos: a eficácia e a mensuração das performances, bem como a elaboração de gestos e técnicas nas intervenções pedagógicas.

Mesmo reconhecendo a pertinência desses argumentos - ou seja, as relações entre medicina, higiene, ciência, educação e ginástica -, sugerimos que não são suficientes para dar conta de entender a complexidade da presença da modalidade no cenário fluminense. Merecem mais atenção algumas facetas que têm sido relegadas a um segundo plano, como a relação da prática com a dimensão espetáculo. 
Para Soares (2009, p.139; destaques no original), por exemplo, embora a "modernidade da ginástica" pudesse também ser constituída "de modo bastante significativo, em sua estreita imbricação entre 'prática' e 'espetáculo'”, em última análise, o olhar deveria se voltar para a "compreensão da extensão dos poderes e saberes gerados pela higiene, dos quais a ginástica é filha mais dileta" (p.134). Para a autora, mesmo que seja "sempre adequado 'recordar' as rupturas profundas que a ginástica vai estabelecendo ao longo do século XIX e início do XX com o mundo da arte", a história mostraria a "sua submissão, quase total, ao mundo da higiene, da medicina e da moral" (p.140; destaque nosso).

Há muitos riscos que cercam essa tendência de olhar a ginástica exclusiva ou majoritariamente a partir dos debates sobre saúde. Um deles é superdimensionar a capacidade de imposição social dos pressupostos médicos. Entre a população, e mesmo no próprio campo da medicina, persistiam muitas práticas "não científicas" e divergências, também com outros sujeitos históricos (como boticários, benzedeiros, curandeiros etc.). As relações entre facultativos, Estado e sociedade não eram lineares, constituindo um conjunto heterogêneo de ideias e ações, sendo marcadas por tensões e ambiguidades (Edler, 1998; Ferreira, 2003; Sampaio, 2001).

Para melhor entender a presença da ginástica na sociedade fluminense do século XIX, vale a pena ter em conta outras questões do momento, como a gestação de uma nova sociabilidade pública e a conformação de um mercado de entretenimentos, fenômenos típicos de sociedades que passaram por processos de modernização, como foi o caso do Rio de Janeiro na segunda metade do século XIX (Schwarcz, 1998). Nesse cenário, deve-se, inclusive, melhor examinar a relação da modalidade com outras práticas corporais institucionalizadas que se delineavam no mesmo momento, como a esgrima, a natação e mesmo com as demais práticas esportivas.

Tendo em conta essas observações iniciais, este artigo objetiva investigar a presença da ginástica em uma escola do Rio de Janeiro do século XIX, buscando prospectar como o debate sobre a saúde nessas instituições se manifestou no Colégio Abílio, um dos mais prestigiosos de sua época. Mais do que descortinar os discursos que cercavam seu oferecimento, procuramos compreender seus diferentes arranjos no cotidiano escolar, intuito que enfrenta um elemento dificultador, qual seja, acessar fontes que permitam nos aproximar melhor do tema.

Assim sendo, para alcançar nosso objetivo, usamos duas fontes de natureza diferenciada: periódicos publicados na cidade e o romance O Ateneu, de Raul Pompéia. Temos clareza de que devemos tratá-las a partir de suas peculiaridades. De toda forma, ambas são representações, construídas a partir de pontos de vista distintos. Esperamos que essa conjugação possa nos ajudar a nos aproximar do que pretendemos investigar.

\section{A ginástica no Colégio Abílio: a imprensa}

Em dezembro de 1873, um jornal de grande circulação assim comentou uma atividade realizada no Colégio Abílio:

Mais um dia de grande e justo regozijo foi para o ilustrado Dr. Abílio Cezar Borges o dia 8 do corrente. Nele efetuou-se a festa colegial de férias, nele várias famílias e convidados visitaram o elegante estabelecimento, louvando o asseio, o espírito de ordem, que se manifestava por toda a parte ... Sua Majestade o Imperador e elevado número de 
famílias já na tarde do dia 7 haviam apreciado a excelência da educação física dada aos alunos desse colégio; vários exercícios, em que se empenharam desde os principiantes até os mais adiantados, entretiveram durante pouco mais de duas horas esse concurso de distintos assistentes (Diário do Rio de Janeiro, 10 dez. 1873, p.2).

Eram emblemáticas essas festividades do Colégio Abílio, eventos nos quais a ginástica ocupava lugar de destaque. As notícias nos periódicos publicados permitem entrever algumas características que marcaram a trajetória do "ilustrado" doutor Abílio Cesar Borges (1824-1891): no âmbito da política imperial, envolvendo suas relações com setores governamentais e autoridades públicas; no campo da educação, como portador de status intelectual, cujas iniciativas extrapolavam o ensino privado e eram consideradas modelo a ser seguido; na esfera social, como fundador e diretor de uma escola reconhecida pelas famílias da "boa sociedade".

Estes "múltiplo pertencimento" e "ação multifacetada" eram atributos que caracterizavam o intelectual no século XIX, considerado capaz de compreender as dinâmicas e os problemas da sociedade de seu tempo. O prestígio adquirido legitimava sua inserção no debate público. O doutor Abílio, nesse sentido, era um sujeito histórico que enreda e é enredado pelos arranjos entre a política do Império e a educação brasileira (Gondra, 2009).

A sua trajetória, contudo, não foi isenta de percalços. Logo após a obtenção do grau de doutor, pela Faculdade de Medicina do Rio de Janeiro, em 1847, sua tese chegou a ser ridicularizada publicamente. Abílio criticou o fato em artigos publicados no Jornal do Commercio. Em reação, a direção da escola de medicina solicitou providências à Câmara dos Deputados, considerando que tais escritos "prodigalizam verdadeiros insultos aos lentes" responsáveis por arguir o seu trabalho (Gazeta Oficial..., 14 jan. 1848, p.1).

Não se sabe ao certo até que ponto tais circunstâncias contribuíram para sua volta à Bahia, sua terra natal, e posterior afastamento do ofício médico. ${ }^{4}$ De toda forma, o doutor Abílio foi cada vez mais se aproximando do campo da educação. Em 1855, foi nomeado diretor de instrução pública daquela província. Em 1858, criou o Ginásio Baiano. Por suas ações, seu nome chegou a ser aventado para assumir a vaga de reitor do Colégio Pedro II (Saviani, 2000).

O retorno à capital do Império, em 1870, e a inauguração do Colégio Abílio, em 1871, são pontos importantes de sua trajetória. No Rio de Janeiro, consagrou-se como um dos mais reconhecidos educadores do país, "cuja dedicação e amor ao ensino firmavam entre nós uma época nova e gloriosa para a mocidade" (Diário do Rio de Janeiro, 27 jul. 1872, p.3).

A ginástica fez parte do cotidiano do Colégio desde seus primeiros momentos. O plano de estudos de 1871 já previa que suas aulas (bem como as de natação) deveriam ser oferecidas para todos os anos do ensino primário e quase todos do secundário (Saviani, 2000). ${ }^{5}$ Vale destacar que a preocupação do doutor Abílio com a educação física já existia quando dirigia o Ginásio Baiano, articulada com a questão da higiene e da saúde, que também tinha conexões com os cuidados com as instalações:

edifício situado em uma chácara muito próxima desta cidade, onde os alunos, por sobre estarem isentos das distrações e desvios a que dá lugar a morada no centro da povoação, terão dilatado espaço para o conveniente exercício corporal e excelentes banhos (Valdez, 2006, p.3). 
De forma semelhante, sobre o Colégio Abílio salientou-se:

na parte material não pode deixar de agradar ainda os mais exigentes; um largo, novo e majestoso edifício, cercado de belas e crescidas árvores e vasto jardim, recebendo luz e ar de todas as faces, presta-se perfeitamente a seu novo destino... Em todo edifício se observa o mais rigoroso asseio (Diário do Rio de Janeiro, 27 nov. 1871, p.1).

Na ocasião, diversas escolas empenhavam-se em destacar tanto a adequação da sua localização quanto o apuro e higiene das instalações (Limeira, 2008). O Colégio Abílio era reconhecido por atender essas dimensões: "Situado em um dos bairros mais salubres, o das Laranjeiras, o edifício onde funcionará ... oferece todas as proporções e comodidades indispensáveis" (A Reforma, 26 jul. 1871, p.2).

A atenção dada a esses aspectos convergia com os discursos sobre saúde e pedagogia da época. Os higienistas associavam ambiente, relações sociais e doença, sendo um dos focos par excellence de suas preocupações os centros urbanos (Czeresnia, 1997). Além disso, parte dos educadores considerava a ideia de distância e reclusão como estratégia pedagógica eficaz (Gondra, Schueler, 2008).

Tais dimensões eram também valorizadas por supostamente serem observadas em nações mais "desenvolvidas": "Confessou o Sr. Dr. Abílio, que muito aprendera observando os melhores estabelecimentos dos países civilizados ... O sistema embora já praticado nos Estados Unidos e em algumas escolas da Europa, é para nós uma novidade" (Diário do Rio de Janeiro, 27 nov. 1871, p.1).

Note-se que o próprio mobiliário do Colégio Abílio era inspirado no que era adotado nesses países. Na Exposição Pedagógica do Rio de Janeiro, realizada em 1883, destacou-se que a escola era organizada à maneira americana, o que incluía armários com coleções de implementos de ginástica, esgrima e jogos diversos. O seu moderno equipamento conferira ao "estabelecimento de instrução talhado nos melhores moldes dos da Europa e América do Norte" o primeiro prêmio na Exposição de Filadélfia e o único na de Paris em 1878 (Gazeta de Notícias, 17 maio 1883, p.2).

O Colégio Abílio rapidamente se tornou um dos mais elogiados da capital:

estou certo de que o ensino primário entre nós nada terá que invejar ao que hoje se distribui nos países que se acham na vanguarda da civilização ... Não me cansarei de louvar o Sr. Dr. Abílio pela sua dedicação ao aperfeiçoamento da educação da mocidade brasileira (Diário do Rio de Janeiro, 12 dez. 1873, p.2).

Um dos pontos mais destacados da proposta do Colégio era exatamente a preocupação com a formação integral, o que incluía iniciativas ligadas à educação do corpo: "Promovendo o desenvolvimento intelectual, não se esquece do desenvolvimento físico e, para alcançar este fim, entrega os alunos sob a sua direção a exercícios variados, que os fortificam" (Diário do Rio de Janeiro, 14 dez. 1873, p.1). Esse aspecto do "Método Abílio" também foi enfatizado pelo renomado editor J.C. de Alambary Luz, em matéria de capa publicada naquele que é considerado o primeiro periódico brasileiro voltado para o campo da educação, A Instrução Pública (12 jan. 1873, p.9):

para quem pouco estuda o crescente alargamento da instrução pública em todos os países adiantados da Europa e dos Estados Unidos parece excessivo e superior às forças 
da infância [mas,] se tudo isto for acompanhado de cautelas pela saúde e robustez dos meninos, então o método Abílio será, como é, o único admissível na instrução primária porque reúne e desempenha os seus três grandes fins; - a educação moral, intelectual e física da infância.

Em muitas oportunidades, as concepções de educação física do Colégio Abílio foram comparadas àquelas levadas a cabo pelo Estado, ressaltando-se, em geral, as carências e o mau funcionamento deste. Vejamos um exemplo:

Enquanto não compreendem os poderes públicos a necessidade imprescindível de dar desenvolvimento ao estudo da ginástica em todos os estabelecimentos de ensino, à imitação do que se pratica no Norte da Europa, e principalmente na Suécia e Alemanha, vai a iniciativa individual rompendo o círculo de ferro de tanta restrição e exigência fútil, em tudo quanto se prende ao derramamento da instrução pública entre nós. ... O resultado é que a nossa mocidade em geral é pálida, fraca e doentia (O Globo, 18 jul. 1876, p.1).

Convém lembrar que, em 1854, a Reforma Couto Ferraz, que estabeleceu novas normas para a educação primária e secundária na Corte, tornara obrigatório o ensino de noções de ginástica na escola pública. Na verdade, associadas a projetos de construção da ideia de nação, desde 1823, entabulavam-se iniciativas governamentais que procuravam materializar uma proposta de educação física. Esta, contudo, pouco avançava, tendo que lidar com as condições concretas do país e com uma burocracia ainda em formação (Peres, Melo, 2014b).

Assim, o doutor Abílio e João Pedro de Aquino (dono do Colégio Aquino) foram elogiados por terem compreendido o valor da ginástica: "a maior e mais urgente de todas as medidas era preparar os meninos para serem homens, na verdadeira acepção que se dá a esta palavra nos países de mais energia, vigor e força de vontade" (O Globo, 18 jul. 1876, p.1). Eles teriam adotado um perfil "adequado" da prática, em contraposição ao que era apresentado nos espetáculos circenses e teatrais:

Ainda há entre nós muita gente que não compreende o alcance e a importância do estudo da ginástica e de todos os exercícios físicos, e esse infeliz preconceito partilhado até por certas camadas sociais que por sua colocação já devem perceber que se não pretende habilitar as crianças para trabalhar nos circos e teatros, mas sim desenvolver-lhe as forças, dando flexibilidade aos músculos, habituando os meninos a não recearem qualquer esforço e a não verem perigo nas coisas mais insignificantes da vida prática e material: em suma, não se quer formar acrobatas, mas homens fortes, vigorosos, ágeis e corajosos (O Globo, 18 jul. 1876, p.1).

A concepção de ginástica do Colégio Abílio tinha relação com uma compreensão da "escola enquanto lugar de cura para uma sociedade descrita sob os marcos da incivilidade, desordem ... e desrazão" (Gondra, 2004, p.12). De acordo com o próprio doutor Abílio, “o corpo é uma máquina complicadíssima, cujo destino é o serviço da mente: e, pois, tanto melhor serviço prestará, quanto mais perfeito, mais forte. Em suma, quanto mais são for" (citado em Saviani, 2000, p.51). Não é fortuito, portanto, que a "educação física metódica" fizesse parte do "Método Abílio" e fosse tão destacada nos anúncios da escola.

Na Gazeta da Tarde de $1^{\circ}$ de março de 1884 (p.4), a propaganda do colégio, que ocupava grande parte da página, mencionava as condições em que se dava o ensino da educação física. ${ }^{6}$ 
Informava, entre outras coisas, o corpo docente, os períodos de ensino (tanto das recreações livres no pátio quanto das atividades dirigidas), os graus e idades em que era lecionada, bem como os métodos usados (na instrução primária eram ministrados exercícios calistênicos; na secundária havia também aulas de evoluções militares, dança, natação e esgrima).

Além do caráter informativo, essa publicidade mobilizava um capital simbólico: ao reforçar a adesão a princípios pedagógicos considerados modernos e civilizados, visava evidenciar a qualidade e diferencial do colégio. É nessa perspectiva que, desde 1877, os anúncios faziam referência aos nomes dos professores, em geral docentes que gozavam de reconhecimento na sociedade da Corte. Eles ajudavam a fortalecer o prestígio da escola.

Três desses professores merecem destaque. O capitão Ataliba Manuel Fernandes atuou com ginástica, evoluções militares e natação no Colégio Abílio. Foi um dos mestres de maior destaque no Rio de Janeiro do século XIX, lecionando também no Colégio Naval, na Academia da Marinha, na Escola Normal da Província, na Escola Normal da Corte, na Escola Militar e na Escola Municipal São Sebastião. Paulo Vidal foi outro grande nome da ginástica no período. Era também docente do Colégio Pedro II, onde se destacou por desempenhar um papel protagonista na reestruturação da disciplina (Cunha Junior, 2008). Já Jules Clément Pontié foi um dos mais respeitados mestres de esgrima da cidade. Lecionava também na Escola Militar e em uma sala particular. Junto com Vidal, atuava ainda no Clube Ginástico Português.

Uma das faces mais visíveis do Colégio Abílio, veiculada constantemente na imprensa - por meio de anúncios ou de notícias -, era mesmo as festas de educação física. Realizadas desde 1872, contribuíam para ampliar o renome da escola e de seu fundador. Esses eventos mereciam referência até mesmo nos folhetins destinados a comentar os acontecimentos sociais mais notáveis da cidade:

Às 5 horas da tarde do dia $7 \mathrm{o}$ vasto recreio onde se acham todos os preparativos ginásticos viu-se concorrido por avultado número de senhoras e cavalheiros, notando-se que aquelas se haviam esmerado em suas toilletes. Depois da chegada de Sua Majestade o Imperador, os alunos começaram a demostrar o como ali recebem uma cuidada educação física. Exercícios diversos executados sobre o chão, sobre as paralelas, sobre a barra fixa, sobre o trapézio, sobre velocípedes etc., abonaram os resultados dessa mesma educação. Com o cair da noite finalizou-se a última parte do programa, mostrando-se todos os assistentes bastante satisfeitos com o que haviam testemunhado (Diário do Rio de Janeiro, 14 dez. 1873, p.1).

Em muitas ocasiões, tais eventos eram abertos ao público em geral: "Essa festa, ao mesmo tempo útil e recreativa, costuma atrair, além das famílias dos alunos, grande número de pessoas que gostam de apreciar os progressos realizados por esse distinto e infatigável educador da mocidade" (O Globo, 26 out. 1876, p.2). As apresentações ajudavam a construir uma rede de sociabilidade ao redor da instituição, sendo também uma estratégia de propaganda.

Os relatos dos jornais, mesmo ressaltando certos princípios pedagógicos, aproximavam-se daqueles que descreviam os espetáculos de teatros e circos: referências a um dia excepcional, ao grande número de presentes, ao esmero dos trajes femininos, à presença de convidados ilustres, ao programa executado, ao contentamento do público. Isso não era ocasional: a ginástica era efetivamente "encenada" nessas ocasiões. 
Vejamos que algumas informações e representações difundidas nos periódicos fluminenses vão de encontro a estudos que tendem a reificar determinadas interpretações - eivadas, em geral, por um olhar romântico e dicotômico - sobre a presença da prática corporal na sociedade fluminense do século XIX. Moreno (2001, p.3; destaque nosso), por exemplo, sugere que:

Havia uma contradição óbvia, visual até, entre as práticas corporais do povo fluminense e a ginástica. Molejo, movimentos do baixo-corporal, ginga, sensualidade, círculos. Animados por uma música sempre motivante, não podiam dialogar com as imagens que podemos ver das sessões de ginástica: alto-corporal sempre valorizado, retidão de movimentos, espaços metrificados ... Por isso, dizia, 'interessou-me o afastamento da ginástica do campo do entretenimento'. Esse afastamento terá sido, talvez, o principal motivo, do Rio de Janeiro ter sido o não-lugar da ginástica. Significa dizer, metaforicamente, que a ginástica, como prática corporal, não encontrou, no corpo do homem fluminense, permissão para alojar-se. Permissão não dada porque nada havia nessa prática que pudesse impactar esse corpo, algo que pudesse gerar um mínimo de identidade.

A descrição dos exercícios nas festas de educação física reforça justamente a percepção de proximidade com os outros espetáculos públicos. Examinemos, por exemplo, o comentário publicado em A Instrução Pública, que se apresentou não como "uma gazeta noticiarista, mas sim um repositório, onde tudo o que interessa ao ensino deve ter e tem sempre um lugar", por isso supostamente lançando um olhar distinto de "todos os jornais [que] deram já notícia da festa anual do Colégio Abílio" (A Instrução Pública, 14 dez. 1873, p.485). O relato, todavia, não deixava dúvida do caráter da exibição:

Os exercícios começaram por diferentes evoluções, que encantaram a todos os presentes: a precisão e rapidez com que os alunos faziam todos os movimentos indicados foram realmente notáveis e iniciou perfeitamente aquela parte das provas. Não menos notáveis foram os exercícios na barra, no trapézio, nas paralelas, nas argolas, na escada, os saltos, as manobras, as corridas, tanto a pé como em velocípede, a luta, enfim tudo o que contribui para o desenvolvimento da força e destreza do homem (A Instrução Pública, 14 dez. 1873, p.485).

O que era apresentado como "metódico" acabava por ganhar formas inspiradas em cenários extraescolares. Não estamos afirmando que a dinâmica era exatamente a mesma. Contudo, é inegável que havia semelhanças, inclusive em função da necessidade de agradar o público, já acostumado a exibições marcadas pelas noções de desafio, surpreendente, inusitado.

Enfim, se a dimensão espetáculo se constituiu, no decorrer do século XIX, em uma importante faceta da ginástica, portadora de uma força simbólica capaz de fazer convergirem determinados valores, estruturas narrativas e experiências estéticas no caso do Colégio Abílio, tal aspecto enredava um projeto educacional que articulava discursivamente preceitos higienistas. A prática "metódica" não conseguia se afastar completamente do que se passava em circos e teatros, mesmo que esses fossem condenados pelos discursos pedagógicos.

Valerá a pena ampliar nosso olhar sobre a presença da ginástica no cotidiano do colégio, tarefa difícil pela escassez de fontes disponíveis. Uma estratégia possível é utilizar um material de natureza diferenciada, entendendo, por certo, os seus limites e peculiaridades. É o que pretendemos fazer ao discutir as representações da ginástica em $O$ Ateneu, de Raul Pompéia. 


\section{A ginástica no Colégio Abílio: O Ateneu}

Muitos são os estudos já desenvolvidos sobre O Ateneu, alguns deles, inclusive, dedicados a problematizar as mais diversas questões da educação. Sobre o romance de Raul Pompéia já se debruçaram importantes intelectuais brasileiros, como Mário de Andrade e Alfredo Bosi. Não surpreende tal interesse: trata-se de uma das mais importantes e originais obras da literatura nacional. ${ }^{7}$

Pompéia era parte do que veio a se chamar de Geração de 1870, um grupo de literatos que concebia sua produção como uma forma de divulgar ideias que pretendiam modernizar a sociedade brasileira. Sintonizados com os princípios do positivismo, muitos deles acreditavam que a república seria a melhor opção para o país (Alonso, 2002).

O Ateneu foi publicado pela primeira vez em 1888, em folhetins da Gazeta de Notícias. O romance narra, a partir das memórias de Sérgio, sua experiência como estudante de um dos mais importantes colégios do Império, dirigido pelo renomado professor Ariostarco, um dos grandes educadores de seu tempo.

Como lembra Ricardo Martins (2011, p.1): “Considerado uma obra-prima, um dos grandes clássicos de nossa literatura, O Ateneu é um livro de difícil classificação quanto a sua filiação estética". Para o autor, o romance apresenta traços do realismo, uma "ácida crítica social e uma nítida preocupação moral com os atos e delitos cometidos pelos personagens"; do expressionismo, "com o uso constante de imagens grotescas, exageradas"; e é predominantemente impressionista: "a narrativa baseia-se em uma observação e perspectiva muito subjetiva, sensível e pessoal da realidade" (Pompéia, 1996, p.2).

Há, no romance, muitos elementos da memória de Raul Pompéia no que se refere a seu tempo de estudante do Colégio Abílio. Devemos lembrar, todavia, que O Ateneu é uma ficção. É uma representação construída a partir de um olhar do autor sobre uma escola, o sistema educacional e as contradições da sociedade fluminense:

aventar a possibilidade de que o romance de Pompéia seja autobiográfico, em sentido puro, é uma postura crítica, no mínimo, apressada e pouco fundamentada, quando não um reducionismo imaturo. Que elementos biográficos sirvam à composição dos personagens e do ambiente ficcional é algo muito distinto de copiá-los in totum da realidade, sem o medium da criação literária (Martins, 2011, p.8).

De toda maneira, o romance apresenta-nos uma possibilidade específica de ter acesso ao cotidiano escolar, notadamente por trazer a memória dramatizada para o centro do exercício literário (Castello, 1995). Como sugere Lucas (1995, p.17):

a narrativa abre janelas para o estudo do cotidiano do Segundo Império brasileiro, oferecendo ao leitor a visada de nossas instituições políticas e educacionais, manifestadas no comportamento dos personagens, na indumentária, nos hábitos do dia a dia e nas elocuções de autoridades públicas e comparsas.

Isto é, mesmo tendo em conta os limites apontados, estamos de acordo com Martins (2011, p.3): "não se pode desprezar o caráter simbólico do romance, repleto de significados sociais e conteúdo existencial muito denso, compondo um painel convincente e vasto, ainda que reduzido ao mundo do internato, da sociedade brasileira do final do Oitocentos". Vale ter em 
conta que Pompéia é "considerado um dos mais lúcidos escritores e intérpretes da estrutura socioeconômica e política da sociedade brasileira de fins do século XIX" (p.3). Enfim, o que não se deve perder de vista é que em $O$ Ateneu:

a linguagem literária é mais importante que os fatores externos à literatura, como a própria sociedade. Não se afirma, com isso, que Pompéia foi insensível aos fenômenos sociais de seu tempo - vimos que é justamente o contrário -, mas somente que a linguagem em O Ateneu não é tomada como um simples e servil instrumento para a enunciação dos elementos narrativos (o enredo, os personagens, a ação, os personagens), passando a ser valorizada em função da dimensão plástica, emotiva e sonora das palavras (Martins, 2011, p.6).

No que se refere à sensibilidade de Pompéia às questões sociais de seu tempo, Fritzen (2005, p.11) sugere que "é o problema do controle dos instintos das crianças o que mais aflora no romance" (p.11). Uma das funções da escola seria a de fazer a passagem da infância para a vida adulta. A própria fala inicial da obra pode ser interpretada nessa perspectiva: "Vais encontrar o mundo, disse-me meu pai, à porta do Ateneu. Coragem e luta" (Pompéia, 1996, p.1).

A presença da ginástica no colégio pode ser também entendida a partir desse prisma. Era concebida como uma das estratégias utilizadas para enquadrar os sentimentos infantis, a partir das noções de higiene, saúde e disciplina. ${ }^{8}$ Da mesma forma, relacionava-se ao fato de que o Ateneu era apresentado como uma instituição sintonizada com o que havia de mais atualizado em seu tempo. O romance sugere, todavia, que o cotidiano era mais tortuoso do que apresentado nos discursos, marcado por muitos conflitos e contradições.

O primeiro contato de Sérgio com o seu futuro colégio se deu em uma ocasião solene: uma festa de encerramento do ano letivo, quando, em meio a discursos e breves apresentações, contando com a presença de pais, professores e autoridades, os alunos se exibiram em traje de gala ${ }^{9}$ para a premiação dos melhores desempenhos. Ele observa: "Como a maior concorrência preferia sempre a exibição dos exercícios ginásticos, solenizada dias depois do encerramento das aulas, a acomodação deixada aos circunstantes era pouco espaçosa" (Pompéia, 1996, p.3).

Essa segunda cerimônia fascinaria ainda mais Sérgio. Segundo seu olhar, "por todos os lados apinhava-se o povo" (Pompéia, 1996, p.5), assistindo a tudo com grande entusiasmo. A performance dos alunos lhe parecia arrebatadora:

Cerca de trezentos; produziam-me a impressão do inumerável. Todos de branco, apertados em larga cinta vermelha, com alças de ferro sobre os quadris e na cabeça um pequeno gorro cingido por um cadarço de pontas livres. Ao ombro esquerdo traziam laços distintivos das turmas. Passaram a toque de clarim, sopesando os apetrechos diversos dos exercícios. Primeira turma, os halteres, segunda, as massas, terceira, as barras. Fechavam a marcha, desarmados, os que figurariam simplesmente nos exercícios gerais. Depois de longa volta, a quatro de fundo, dispuseram-se em pelotões, invadiram o gramal, e, cadenciados pelo ritmo da banda de colegas, que os esperava no meio do campo, com a certeza de amestrada disciplina, produziram as manobras perfeitas de um exército sob o comando do mais raro instrutor (Pompéia, 1996, p.5).

Dirigindo o espetáculo, o professor Bataillard apresentou-se trajado elegantemente. Era a perfeita incorporação dos princípios da cerimônia, tudo o que se podia esperar de um mestre de ginástica: 
exultava envergando a altivez do seu sucesso na extremada elegância do talhe, multiplicando por milagroso desdobramento o compêndio inteiro da capacidade profissional, exibida em galeria por uma série infinita de atitudes. A admiração hesitava a decidir-se pela formosura masculina e rija da plástica de músculos a estalar o brim do uniforme, que ele trajava branco como os alunos, ou pela nervosa celeridade dos movimentos, efeito elétrico de lanterna mágica, respeitando-se na variedade prodigiosa a unidade da correção suprema (Pompéia, 1996, p.5).

A ginástica era apresentada como uma prática "metódica" e "racional", exemplo dos princípios que norteavam o funcionamento do Ateneu. O público, todavia, parecia valorizar mesmo o espetáculo dos corpos a desfilar em notáveis performances. A escola não conseguiria ficar inerte ao que vinha de fora. Aliás, um dos personagens fulcrais do romance, doutor Cláudio, em uma de suas conferências observa: "Não é o internato que faz a sociedade; o internato a reflete" (Pompéia, 1996, p.97).

O olhar de Sérgio sobre a festa de educação física é marcado por ambiguidades. O entusiasmo era incontinente: "O coração pulava-me no peito com um alvoroço novo, que me arrastava para o meio dos alunos, numa leva ardente de fraternidade. Eu batia palmas; gritos escapavam-me, de que me arrependia quando alguém me olhava" (Pompéia, 1996, p.6). De outro lado, observa a hierarquia e a ordem, que tinha à frente o mestre Bataillard: ${ }^{10}$

Ele dava as ordens fortemente, com uma vibração penetrante de corneta que dominava a distância, e sorria à docilidade mecânica dos rapazes. Como oficiais subalternos, auxiliavam-no os chefes de turma, postados devidamente com os pelotões, sacudindo à manga distintivos de fita verde e canutilho (Pompéia, 1996, p.5).

Chamava-lhe a atenção a exibição coordenada dos corpos: "Músculos do braço, músculos do tronco, tendões dos jarretes, a teoria toda do corpore sano foi praticada valentemente ali, precisamente, com a simultaneidade exata das extensas máquinas" (Pompéia, 1996, p.5). Mas também lhe empolgava a descontração do momento:

Não posso dar ideia do deslumbramento que me ficou desta parte. Uma desordem de contorções, deslocadas e atrevidas; uma vertigem de volteios à barra fixa, temeridades acrobáticas ao trapézio, às perchas, às cordas, às escadas; pirâmides humanas sobre as paralelas, deformando-se para os lados em curvas de braços e ostentações vigorosas de tórax; formas de estatuária viva, trêmulas de esforço, deixando adivinhar de longe o estalido dos ossos desarticulados; posturas de transfiguração sobre invisível apoio; aqui e ali uma cabecinha loura, cabelos em desordem cacheados à testa, um rosto injetado pela inversão do corpo, lábios entreabertos ofegando, olhos semicerrados para escapar à areia dos sapatos, costas de suor, colando a blusa em pasta, gorros sem dono que caíam do alto e juncavam a terra (Pompéia, 1996, p.6).

Por sua descrição, o desenrolar da festa é significativamente menos ordeiro do que a princípio se apresentava. A aquisição e o desenvolvimento de habilidades corporais entre os alunos não eram homogêneos como poderia parecer em um primeiro momento:

Foi de ver-se os jovens atletas aos pares aferrados, empuxando-se, constringindo-se, rodopiando, rolando na relva com gritos satisfeitos e arquejos de arrancada; os corredores, alguns em rigor, respiração medida, beiços unidos, punhos cerrados contra o corpo, passo miúdo e vertiginoso; outros, irregulares, bracejantes prodigalizando pernadas, rasgando 
o ar a pontapés, numa precipitação desengonçada de avestruz, chegando estofados, com placas de poeira na cara, ao poste da vitória (Pompéia, 1996, p.6).

A própria dinâmica da exibição de práticas corporais, ainda que delas se esperasse ser uma estratégia de disciplinamento, instituía um ambiente mais alegre e menos formal, perceptível inclusive na diferença de postura do diretor:

Aristarco arrebentava de júbilo. Pusera de parte o comedimento soberano que eu the admirara na primeira festa. De ponto em branco, como a rapaziada, e chapéu-do-chile, distribuía-se numa ubiquidade impossível de meio ambiente ... O figurino campestre rejuvenescera-o. Sentia as pernas leves e percorria celerípede a frente dos estrados, cheio de cumprimentos para os convidados especiais e de interjetivos amáveis para todos (Pompéia, 1996, p.6).

Depois dessa experiência, Sérgio ficara convencido de que queria fazer parte daquele grupo: "uma consequência apaixonada da sedução do espetáculo, o arroubo de solidariedade que me parecia prender à comunhão fraternal da escola" (Pompéia, 1996, p.7). No cotidiano do colégio, todavia, as coisas não eram tão belas como pareciam ser na apresentação: "Honrado engano, esse ardor franco por uma empresa ideal de energia e de dedicação premeditada confusamente" (p.7). No internato, tinha que aprender a lidar com várias formas de violência, inclusive de natureza sexual.

Rebelo, o primeiro do qual Sérgio aproximou-se no internato, logo o alerta: "Olhe; um conselho; faça-se forte aqui, faça-se homem. Os fracos perdem-se" (Pompéia, 1996, p.14). Não se trata de uma dica somente metafórica. O protagonista teria que aprender a se defender para evitar dissabores:

Os gênios fazem aqui dois sexos, como se fosse uma escola mista. Os rapazes tímidos, ingênuos, sem sangue, são brandamente impelidos para o sexo da fraqueza; são dominados, festejados, pervertidos como meninas ao desamparo. Quando, em segredo dos pais, pensam que o colégio é a melhor das vidas, com o acolhimento dos mais velhos, entre brejeiro e afetuoso, estão perdidos... Faça-se homem, meu amigo! Comece por não admitir protetores (Pompéia, 1996, p.14).

Nesse sentido, a força física era instrumento de segurança, para além do que era concebido nos discursos que cercavam a ginástica. Ficamos sabendo que os exercícios eram realizados diariamente, uma hora depois do jantar. Antes ou após as lições do professor Bataillard, vigiados por inspetores, os alunos desfrutavam de alguns momentos livres de recreação.

Sérgio, fraco e franzino, não conseguiu seguir o conselho de Rebelo. Logo sua fragilidade veio à tona, exatamente no horário da natação: "chamava-se o banheiro, construído num terreno das dependências do Ateneu, vasta toalha d'água ao rés da terra, trinta metros sobre cinco, com escoamento para o Rio Comprido, e alimentada por grandes torneiras de chave livre" (Pompéia, 1996, p.18). Ele reflete:

Se em pequeno, movido por um vislumbre de luminosa prudência, enquanto aplicavam-se os outros à peteca, eu me houvesse entregado ao manso labor de fabricar documentos autobiográficos, para a oportuna confecção de mais uma infância célebre, certo não registraria, entre os meus episódios de predestinado, o caso banal da natação; de consequências, entretanto, para mim, e origem de dissabores como jamais encontrei tão amargos (Pompéia, 1996, p.18). 
O protagonista narra com detalhes os momentos dos banhos, normalmente ocasiões festejadas pelos alunos. As cenas carregam até mesmo certo erotismo:

turbulento debate de corpos nus, estreitamente cingidos no calção de malha rajado a cores, enleando-se os rapazes como lampreias, uns imergindo, reaparecendo outros, olhos injetados, cabelos a escorrer pela cara, vergões na pele de involuntárias unhadas dos companheiros (Pompéia, 1996, p.18).

A despeito do clima de alegria, havia certa tensão: "Dos maiores, alguns havia que faziam medo realmente, singrando a braçadas, levando a ombro a resistência d'água; outros se precipitavam de cabeça para baixo, volteando os pés no ar como cauda de peixe, prancheando sem ver a quem" (Pompéia, 1996, p.18). Segundo as memórias de Sérgio, o inspetor não dava conta de fiscalizar a divisão por idades que havia nos banhos, "de sorte que ficavam expostos os mais fracos aos abusos dos marmanjos que as espadanas d'água acobertavam" (p.18).

O protagonista quase se afoga numa dessas "brincadeiras", sendo salvo por Sanches, um menino mais velho, que por tal motivo lhe impôs uma relação próxima. Como observa:

Tive depois motivo para crer que o perverso e a peste fora-o ele próprio, na intenção de fazer valer um bom serviço. Mas a consequência imediata do fato foi que forcei a repugnância que o Sanches me causava e me fiz todo gratidão para com ele e íntima amizade. Curiosa e acidentada tinha de ser essa minha aventura de apego e confiança (Pompéia, 1996, p.19).

Sérgio percebe que a força física era mesmo um elemento de destaque no cenário escolar ("Os fortes constituem realmente uma fidalguia de privilégios no internato"), superando até mesmo outras distinções ("Os títulos de superioridade prevalecem primitivamente no critério semibárbaro dos verdes anos; o punho válido chega a fazer vantagem sobre a própria vantagem do favoritismo"). Tratava-se da "tribo dos acrobatas, dos atletas; ... que localizava na protuberância nodosa do bíceps o pundonor supremo da criatura" (Pompéia, 1996, p.47). ${ }^{11}$ Uma vez mais a figura de linguagem resvala naquilo que nos discursos oficiais se queria afastar: o circo.

As habilidades físicas marcavam a identidade e o prestígio dessa "tribo": "Aquele é o Malheiro, um grande em ginástica ... Forte como um touro, todos o temem, muitos o cercam, os inspetores não podem com ele; o diretor respeita-o; faz-se a vista larga para os seus abusos" (Pompéia, 1996, p.14). Esse jovem, o "herói do trapézio" (p.19), era um dos "vigilantes", ajudantes de Aristarco na manutenção da ordem no colégio. Um dos critérios para escolhêlos era mesmo a "valentia à barra fixa" (p.19).

Outro que se destacava por seu desempenho nas sessões de ginástica, reconhecido (e temido) pela força e compleição muscular, era Bento Alves, que, por determinado tempo, tornou-se o principal amigo de Sérgio. O seu comportamento inspirava um respeito ainda maior:

Alves não alardeava de forte; evitava disputas, não jogava o pulso, preferia exercitar-se à ginástica sem espectadores. Às vezes, por brinquedo, cingia o braço a um colega entre o polegar e o médio e fechava-lhe sob a manga um bracelete roxo dolorido. Aqueles que se sujeitavam ao formidável ensaio de tatuagem por compressão, acercavam-se, daí por diante, de Bento Alves com os escrúpulos da mais reservada prudência (Pompéia, 1996, p.47). 
Bento Alves, aliás, ficou contrariado por ter se tornado um herói, ao intervir em um incidente entre funcionários do Ateneu. A proeza aumentou a inveja de Malheiros, que com ele disputava o protagonismo ginástico do colégio:

A preocupação de Bento Alves era uma injúria. Entre ele e Malheiro havia rixa de velha de emulação. Malheiro não lhe perdoava a culpa de ser bravo. Os próprios prodígios da força e agilidade, aplaudidos e proclamados pelo Ateneu, não davam para saciar a vaidade. De que valia ser forte, se era impossível a aplicação do seu esforço para afrouxar uma fibra à musculatura do Bento? Ah! não ser possível por sugestão desfiar uma a uma aquelas meadas de arame, reduzir a infantilidade débil aquela corpulência odiosa! Por que não iriam os desejos da inveja, como vampiros, sorver o sangue àquela força, a vida, gota a gota, àquele vigor de ferro? (Pompéia, 1996, p.59).

O imbróglio entre os dois foi resolvido em uma briga, que envolvia também Sérgio (ridicularizado pela amizade "muito próxima" com Alves). ${ }^{12}$ Ao fim, Bento saiu ferido por uma navalha, mas desmaiara Malheiros com socos. Ambos foram punidos: aos olhos da direção, era inaceitável essa exibição indisciplinada de força, contrária aos princípios "civilizados" propugnados.

Outro caso sintomático da importância da ginástica no cotidiano do Ateneu foi a chegada de Nearco da Fonseca, apresentado por seu pai como um grande atleta, o que causou surpresa dada a sua compleição física: "Talentoso que fosse, concebíamos, se por nada mais, ao menos pela cabeleira... Mas um ginasta aquele espectro da necessidade!" (Pompéia, 1996, p.47).

Todo o colégio mobilizou-se para ver a exibição do novo aluno, que solenemente se preparou para demonstrar sua capacidade:

Nearco deixou a forma, rompendo a marcha com o pé esquerdo, a regra, mãos à ilharga, sério como um bispo, e encaminhou-se para o trapézio com o passo medido das emas, imperturbável como quem sabe profundamente a técnica do marchar. Perto do aparelho, sempre de mãos à cinta, volta a volver! virou-se para o colégio, teso, e quebrou para nós um duro salamaleque, conservando por segundos a efracção angular das figurinhas delineadas, representando a lavoura, na cantaria histórica do Egito (Pompéia, 1996, p.47).

Na hora de se apresentar publicamente, no momento da comparação com os outros homens, fez uma série de flexões e cambalhotas, demonstrando até alguma habilidade. ${ }^{13}$ Todavia, não tinha a força necessária para fazer exercícios mais elaborados:

Faltava a sorte do fim. Nearco espichou quanto pôde a lamentável ausência de músculos e deu-nos... uma sereia! A sereia é tudo que há de mais elementar, de mais pulha, de mais tolamente ostentoso em matéria de aparelhos. O sujeito segura-se às cordas, levanta os pés da barra, mete os pés pelas mãos e de cabeça para a terra empurra o ventre. O pobre Nearco, desbarrigado, não tinha ventre para empurrar. Não empurrou coisa nenhuma; quando muito uns ossinhos que lhe saíam à altura do umbigo como cabos de faca. Pulou ao chão (Pompéia, 1996, p.48).

O jovem só não foi imediatamente motivo de chacotas graças à intervenção de Ariostarco, que não queria constrangimentos com o pai de Nearco, que assistiu a tudo com indisfarçável orgulho. As palmas contidas, todavia, davam a perceber o que viria: sua fracassada demonstração seria sempre lembrada com jocosidade. Ele somente se reabilitaria frente aos colegas 
quando demonstrou habilidades literárias e retóricas nas sessões do grêmio "Amor ao Saber". Jamais seria, contudo, reconhecido como integrante da "elite ginástica" do Ateneu.

Enfim, no romance é possível entrever que diversos interesses e ambiguidades cercavam a presença da ginástica no cotidiano do Ateneu. Para os dirigentes, era um instrumento para estabelecer o controle e a hierarquia; ao mesmo tempo, ajudava a assegurar o prestígio do colégio, por ser uma expressão de sua sintonia com o que havia de mais avançado no que se refere a parâmetros de civilidade: disciplina, saúde e higiene. Para parte dos alunos, era uma ferramenta para melhor enfrentar a turba e as tensões escolares, bem como um elemento - simbólico e material - de distinção, assédio e intimidação. O público, nas festas de encerramento, gostava mesmo é das exibições audazes, a exemplo do que via nos circos e teatros. Ao que parece, os exercícios ginásticos não eram uma coisa ou outra. Eram todas essas coisas entrecruzadas.

\section{Considerações finais}

Uma das chaves para compreender o ensino da ginástica em instituições escolares na cidade do Rio de Janeiro do século XIX passa, por certo, pelos discursos pedagógicos e médicohigienistas cujas "raízes" se encontravam no Velho Mundo (Soares, 2004, 2009; Gondra, 2004).

Disciplina, saúde, higiene: esses eram princípios que integravam os discursos de defesa e valorização da ginástica, constantemente mobilizados por alguns médicos, dirigentes e intelectuais. Nessa esfera de compreensão, a prática não podia ser confundida com aquela que era exibida em circos e teatros.

Contudo, esses discursos nem sempre, ou muitas vezes, materializavam-se ipsis litteris no cotidiano escolar, não só porque a ginástica era ressignificada pelos alunos, a partir de suas necessidades concretas, como porque os próprios dirigentes faziam outros usos da prática, a partir de seus interesses específicos. Não devemos negligenciar o fato de que frente a uma proposta de rigidez corporal também se manifestasse um corpo transgressor, que dialogava com outras experiências sociais.

Deve-se considerar o papel dos espetáculos na gestação de um (novo) ethos corporal. No decorrer do século XIX, tornaram-se comuns e muito apreciadas na cidade as apresentações de circos que destacavam proezas ginásticas como uma atração (Silva, 2007; Peres, Melo, 2014a). Mesmo que essa "ginástica-exibição" não tivesse grande número de praticantes, sempre cativou um público ávido por novidades. Antes dos exercícios oferecidos em escolas e clubes, gestou-se ao seu redor uma sensibilidade para a modalidade.

A especificidade desses espetáculos ginásticos é que seu poder de sedução estava atrelado diretamente ao corpo per se, o que incomodava alguns intelectuais, que desejavam anexar à prática uma base moral. Devemos lembrar que "a crítica aos exageros do desenvolvimento muscular por ele mesmo e ao funambulismo é ponto passível em todos os educadores que pensaram a educação física escolar nesse momento de transição da sociedade brasileira" (Herold Junior, 2005, p.247). Para o público, todavia, isso não era um problema. Mesmo quando cresceram as contestações, continuou sendo observável a influência das exibições circenses nos mais distintos âmbitos. 
Talvez possamos argumentar, como apontado em outra ocasião (Peres, Melo, 2014c), que a relação entre ideias, estrutura e formação social fez com que a ginástica tivesse um "sentido particular" na dinâmica social fluminense do século XIX, embora com semelhanças com outros países (Peres, Melo, 2014b). A "lenta difusão" de que falam Vigarello e Holt (2008, p.406) parece não apenas ter ganhado novos contornos, como possivelmente se deu de maneira bem eclética e complexa. Por isso, talvez devamos adotar certa cautela, algo próximo ao que os autores assinalaram sobre a disseminação de "uma postura física e na saúde" associada à ginástica: "São tantos sinais que confirmam a discrição, quando não os limites, das renovações".

De toda forma, os indicadores colhidos, ligados a um importante colégio do Rio de Janeiro do século XIX, reforçam a ideia de que a ginástica era presença marcante naquele cenário. Havia, aliás, muitas ginásticas coexistindo. Parece importante, portanto, seguirmos entabulando esforços no sentido de prospectar a miríade de significados que as cercavam, tanto como esferas distintas quanto a partir de seus encontros e cruzamentos de referências, processo relacionado a uma sociedade que cada vez mais ocupava a cena pública, inclusive para desfrutar dos prazeres oferecidos por um mercado de entretenimento em formação.

\section{AGRADECIMENTO}

Pesquisa realizada no âmbito do Sport: Laboratório de História do Esporte e do Lazer/UFRJ. Disponível em: www.sport.ifcs.ufrj.br.

\section{NOTAS}

${ }^{1}$ A partir da Guerra do Paraguai, essas dimensões também se articularam com preocupações com a defesa nacional (Silva, Melo, 2011).

2 Semanário de Saúde Pública (1831-1833), Revista Médica Fluminense (1835-1841), Revista Médica Brasileira (1841-1843), Anais de Medicina Brasiliense (1845-1849) e Anais Brasilienses de Medicina (1849-1885).

${ }^{3}$ Um inventário dos supostos benefícios da ginástica para o trato de moléstias, presentes nos periódicos médicos do século XIX, pode ser prospectado em Peres e Melo (2014a).

${ }^{4}$ Apesar de, na década de 1850, ter abandonado o exercício da medicina, o status proveniente da profissão, bem como a mobilização de saberes médicos, sempre esteve presente ao longo da trajetória do doutor Abílio.

${ }^{5}$ O delegado da Freguesia da Glória informou que, em 1871, havia 59 alunos matriculados no Colégio Abílio (43 na instrução primária e 16 na secundária). Todos cursaram a disciplina ginástica (Figueiredo, 1872).

${ }^{6}$ Nessa ocasião, o colégio já se transferira para Botafogo, e o doutor Abílio estava dirigindo uma filial em Barbacena. Sempre sob sua supervisão, seus filhos ficaram responsáveis pela direção da escola da Corte até sua extinção, em 1911 (Saviani, 2000).

${ }^{7}$ Neste artigo trabalhamos com a 16 a edição da Editora Ática (1996), que está disponível na Biblioteca Virtual do Estudante Brasileiro: http://www.bibvirt.futuro.usp.br. As páginas são referentes à versão eletrônica. Ver Pompéia (1996).

${ }^{8}$ Um debate sobre essa dimensão pode ser visto no estudo de Santos e Marchi (2011, p.4): “a disciplina pode ser pensada como elemento fundamental de entrada e de exercício da atividade ginástica".

${ }^{9}$ Observa Sérgio: "A bela farda negra dos alunos, de botões dourados, infundia-me a consideração tímida de um militarismo brilhante, aparelhado para as campanhas da ciência e do bem" (Pompéia, 1996, p.3).

${ }^{10}$ Em vários momentos da trama, ressalta-se o quanto o professor era rigoroso e disciplinador.

${ }^{11}$ Importa observar que Sérgio registra que alguns colegas eram também conhecidos como sportmen, dado seu envolvimento com a prática esportiva.

${ }^{12}$ Sérgio, aliás, assume sua admiração pelo colega: "A amizade do Bento Alves por mim, e a que nutri por ele, me faz pensar que, mesmo sem o caráter de abatimento que tanto indignava ao Rebelo, certa efeminação 
pode existir como um período de constituição moral. Estimei-o femininamente, porque era grande, forte, bravo; porque me podia valer; porque me respeitava, quase tímido, como se não tivesse ânimo de ser amigo" (Pompéia, 1996, p.51).

${ }^{13}$ Como diz Sérgio: “Ah! não sabeis, profanos que sois, quanto vale a flexão dos membros superiores! A fórmula no mundo ideal da mecânica é a alavanca de Arquimedes; da aplicação prática e contundente é o marro 'britânico'" (Pompéia, 1996, p.47).

\section{REFERÊNCIAS}

A INSTRUÇÃO PÚBLICA.

A Instrução Pública, p.485. 14 dez. 1873.

A INSTRUÇÃO PÚBLICA.

A Instrução Pública, p.9. 12 jan. 1873.

ALONSO, Ângela.

Ideias em movimento: a geração 1870 na crise do Brasil-Império. São Paulo: Paz e Terra. 2002.

A REFORMA.

A Reforma, p.2. 26 jul. 1871.

CASTELLO, José Aderaldo.

Memória e ficção: de Raul Pompéia a José Lins do Rego. Remate de Males, v.15, p.33-44. 1995.

CUNHA JUNIOR, Carlos Fernando F.

Imperial Colégio de Pedro II: o ensino secundário da boa sociedade brasileira. Rio de Janeiro: Apicuri. 2008.

CZERESNIA, Dina.

Do contágio à transmissão: uma mudança na estrutura perceptiva de apreensão da epidemia. História, Ciências, Saúde - Manguinhos, v.4, n.1, p.75-94. 1997.

DIÁRIO DO RIO DE JANEIRO.

Diário do Rio de Janeiro, p.1. 14 dez. 1873.

DIÁRIO DO RIO DE JANEIRO.

Diário do Rio de Janeiro, p.2. 12 dez. 1873.

DIÁRIO DO RIO DE JANEIRO.

Diário do Rio de Janeiro. 10 dez. 1873.

DIÁRIO DO RIO DE JANEIRO.

Diário do Rio de Janeiro, p.3. 27 jul. 1872.

DIÁRIO DO RIO DE JANEIRO.

Diário do Rio de Janeiro, p.1. 27 nov. 1871.

EDLER, Flavio C.

A medicina brasileira no século XIX: um balanço historiográfico. Asclepio, v.50, n.2, p.169-186. 1998.

FERREIRA, Luiz Otávio.

Medicina impopular: ciência médica e medicina popular nas páginas dos periódicos científicos (1830-1840). In: Chalhoub, Sidney et al. (Org.). Artes e ofícios de curar no Brasil: capítulos de história social. Campinas: Unicamp. p.101-122. 2003.
FIGUEIREDO, José Bento C.

Relatório da Inspetoria Geral da Instrução Primária e Secundária do Município da Corte apresentado em 1872. In: Brasil. Ministério do Império. Ministro (João Alfredo Corrêa de Oliveira). Relatório do ano de 1871, apresentado a assembleia geral legislativa na $4^{a}$ sessão da $14^{a}$ legislatura. p.A-B3-3. Disponível em: http://brazil. crl.edu/bsd/bsd/u1698/. Acesso em: 17 jun. 2014. 1872 .

FRITZEN, Celdon.

Imagens da criança na geração de 1870: o problema dos instintos. In: Seminário Educação, Imaginação e as Linguagens Artístico-Culturais, 1., 2005, Criciúma. Anais... Criciúma: Unesc. p.1-15. 2005.

GAZETA DA TARDE. Gazeta da Tarde, p.4. $1^{\circ}$ mar. 1884.

GAZETA DE NOTÍCIAS.

Gazeta de Notícias, p.2. 17 maio 1883.

GAZETA OFICIAL...

Gazeta Oficial do Império do Brasil, p.1. 14 jan. 1848.

GONDRA, José G.

Instrução e intelectualidade no Império brasileiro. In: Vago, Tarcísio Mauro et al. (Org.). Intelectuais e escola pública no Brasil. Belo Horizonte: Mazza. p.160-180. 2009.

GONDRA, José G.

Artes de civilizar: medicina, higiene e educação escolar na Corte Imperial. Rio de Janeiro: Eduerj. 2004.

GONDRA, José G; SCHUELER, Alessandra. Educação, poder e sociedade no Império brasileiro. São Paulo: Cortez. 2008.

HEROLD JUNIOR, Carlos.

Da instrução à educação do corpo: o caráter público da educação física e a luta pela modernização do Brasil no século XIX, 18801915. Educar em Revista, n.25, p.237-255. 2005.

LIMEIRA, Aline M.

O comércio da instrução: práticas educativas e publicidade no século XIX. Linguagens, Educação e Sociedade, ano 13, n.18, p.84-102. 2008. 
LUCAS, Fábio.

As várias faces de Raul Pompéia e O Ateneu. Remate de Males, v.15, p.13-30. 1995.

MARTINS, Ricardo André F.

O Ateneu: representações da memória e do homoerotismo. Litteris, n.7, p.1-15. 2011.

MORENO, Andrea.

Corpo e ginástica num Rio de Janeiro: mosaico de imagens e textos. Motrivivência, n.15, p.1-4. 2001.

O GLOBO.

O Globo, p.2. 26 out. 1876.

O GLOBO.

O Globo, p.1. 18 jul. 1876.

PERES, Fabio de Faria; MELO, Victor Andrade de. A ginástica no tempo do Império. Rio de Janeiro: 7 Letras; Faperj. 2014a.

PERES, Fabio de Faria; MELO, Victor Andrade de. O corpo da nação: posicionamentos governamentais sobre a educação física no Brasil monárquico. História, Ciências, Saúde Manguinhos, v.21, n.4, p.1131-1149. 2014b.

PERES, Fabio de Faria; MELO, Victor Andrade de. A introdução da ginástica nos clubes do Rio de Janeiro do século XIX. Revista Movimento, v.20, n.2, p.471-493. 2014c.

POMPÉIA, Raul.

O Ateneu. São Paulo: Ática. 1996.

RAUCH, André.

Le souci du corps: histoire de l'hygiène en éducation physique. Paris: PUF. 1983.

SAMPAIO, Gabriela R.

Nas trincheiras da cura: as diferentes medicinas no Rio de Janeiro imperial. Campinas: Editora da Unicamp. 2001.

SANTOS, Tiago R.; MARCHI, Rita de Cássia. O Ateneu: uma análise de mecanismos disciplinares no romance de Raul Pompéia. In: Colóquio Ensino Médio, História e Cidadania, 6., Florianópolis. Anais... Udesc. 2011.

SAVIANI, Dermeval.

Um barão brasileiro no Congresso Pedagógico Internacional de Buenos Aires: as ideias pedagógicas de Abílio César Borges, barão de Macaúbas. História da Educação, v.4, n.7, p.41-58. 2000.

SCHWARCZ, Lilia M.

As barbas do imperador: dom Pedro II, um monarca nos trópicos. São Paulo: Companhia das Letras. 1998.

SILVA, Carlos Leonardo B.; MELO, Victor

Andrade de.

Fabricando o soldado, forjando o cidadão: o doutor Eduardo Augusto Pereira de Abreu, a Guerra do Paraguai e a educação física no Brasil. História, Ciências, Saúde-Manguinhos, v.18, n.2, p.337-354. 2011

SILVA, Erminia.

Circo-teatro: Benjamin de Oliveira e a teatralidade circense no Brasil. São Paulo: Altana. 2007.

SOARES, Carmem Lúcia.

Da arte e da ciência de movimentar-se: primeiros movimentos da ginástica no Brasil. In: Del Priore, Mary; Melo, Victor Andrade de (Org.). História do esporte no Brasil: do Império aos dias atuais. São Paulo: Edunesp. p.133-178. 2009.

SOARES, Carmem Lúcia.

Educação física: raízes europeias e Brasil. Campinas: Autores Associados. 2004.

VIGARELLO, Georges.

Préface. In: Arnal, Thierry. La révolution des mouvements: gymnastique, morale et démocratie au temps d'Amoros, 1818-1838. Paris: L'Harmattan. p.7-9. 2009.

VIGARELLO, Georges.

Le corps redressé: histoire d'un pouvoir pédagogique. Paris: Armand Colin. 2004.

VIGARELLO, Georges.

A invenção da ginástica no século XIX: movimentos novos, corpos novos. Revista Brasileira de Ciências do Esporte, v.25, n.1, p.9-20. 2003a.

VIGARELLO, Georges.

A história e os modelos do corpo. Pró-posições, v.14, n.2, p.21-29. 2003b.

VIGARELLO, Georges; HOLT, Richard.

O corpo trabalhado: ginastas e esportistas no século XIX. In: Corbin, Alain; Courtine, JeanJacques; Vigarello, Georges (Org.). História do corpo. Rio de Janeiro: Vozes. v.2. p.393-478. 2008.

VALDEZ, Diane.

Mens sana in corpore sano: os colégios do Dr. Abilio Cesar Borges, o barão de Macaúbas, 18581891. Revista HISTEDBR. Disponível em: http:// www.histedbr.fae.unicamp.br/navegando/ periodo_imperial.html. Acesso em: 17 jun. 2014. 2006.

\section{$\rightarrow \rightarrow+<<<$}

